\title{
Angiotensin II type I receptor blocker, Losartan, inhibits fibrosis in liver by suppressing TGF-beta1 production
}

\author{
Hisanobu Ogata ${ }^{1,2,3 *}$, Hideko Noguchi ${ }^{1}$, Toshio Ohtsubo ${ }^{1}$, Jiyuan Liao ${ }^{2}$, Hiroshi Kohara ${ }^{4}$, Kazunari Yamada ${ }^{2,3}$, Mutsunori Murahashi ${ }^{2,3}$, \\ Yasuki Hijikata $^{2,3}$, Atsushi Suetsugu ${ }^{5}$, Robert M Hoffman ${ }^{6,7}$ and Kenzaburo Tani ${ }^{2,3,4}$ \\ ${ }^{1}$ Department of Medicine and Clinical Science, Graduate School of Medical Sciences, Kyushu University, Fukuoka, 812-8582, Japan \\ ${ }^{2}$ Division of Molecular and Clinical Genetics, Department of Molecular Genetics, Medical Institute of Bioregulation, Kyushu University, Fukuoka, 812-8582, Japan \\ ${ }^{3}$ Department of Advanced Cell and Molecular Therapy, Kyushu University Hospital, Fukuoka 812-8582, Japan \\ ${ }^{4}$ Project Division of ALA Advanced Medical Research, The Institute of Medical Science, The University of Tokyo, Tokyo 108-8639, Japan \\ ${ }^{5}$ Department of Gastroenterology/Internal Medicine, Gifu University Graduate School of Medicine, Gifu, 501-1194, Japan \\ ${ }^{6}$ Department of Surgery, University of California San Diego, School of Medicine, San Diego, CA 92103, USA \\ ${ }^{7}$ AntiCancer, Inc., 7917 Ostrow Street, San Diego, CA 92111, USA
}

\begin{abstract}
Renin-angiotensin system is involved in liver fibrogenesis through activating hepatic stellate cells (HSCs). Losartan, which is an angiotensin II type 1 receptor antagonist, could function as a selective peroxisome proliferator-activated receptor c activator. Here we studied the effect of losartan on liver fibrosis in vivo. In vivo study, we used the Concanavalin A (Con A)-induced mouse liver fibrosis model through $\mathrm{T}$ cell activation and upregulation of TGF- $\beta 1$. The mice were administrated ConA for 4 weeks to induce liver fibrosis, and then co-administrated with losartan. Losartan prevented liver fibrogenesis and downregulated TGF- $\beta 1$ expression. Also, Losartan inhibited HSCs activation and proliferation. These results suggested that Losartan prevent liver fibrosis through suppressing TGF- $\beta 1$ expression.
\end{abstract}

\begin{abstract}
Abbreviations: AT1-R, angiotensin II type 1 receptor; ARB: angiotensin II receptor blocker; RAS: renin-angiotensin system; TGF- $\beta 1$ : transforming growth factor $\beta 1$; NASH: non-alcoholic steatohepatitis
\end{abstract}

\section{Introduction}

Liver fibrosis is the common histological feature of most chronic liver diseases, and leads to cirrhosis and hepatocellular carcinoma (HCC) [1]. Liver cirrhosis is the end stage of chronic liver diseases. Liver fibrosis is the common pathological basis of numerous chronic liver diseases including viral liver disease, alcoholic, non-alcoholic steatohepatitis (NASH), autoimmune hepatitis, primary biliary cirrhosis, and metabolic disease. Liver cirrhosis is characterized by the increase and excessive deposition of the liver extracellular matrix (ECM) [2-4].

Excessive activation of transforming growth factor- $\beta$ (TGF- $\beta$ ) increases the synthesis and decreases the degradation of ECM proteins with a gradual destruction of organ tissue and structure [5]. The major source of ECM deposition in the liver is hepatic stellate cells (HSCs). After liver injury, TGF- $\beta 1$ promotes the activation and proliferation of hepatic HSCs [6]. High levels of TGF- $\beta 1$ are often found in liver fibrosis and there may be a positive correlation between the elevation of TGF- $\beta 1$ mRNA level and fibrogenic activity [7]. Thus, synthesis of ECM proteins increases in the liver due to excessive activation of the TGF- $\beta 1$ signal transduction pathway. Therefore, this pathway has become a potential target for the treatment of the liver fibrosis.
The renin-angiotensin system (RAS) plays an important role in controlling liver fibrosis [8]. It is well known that the RAS influences cell differentiation, nutrition, and fibrosis, and it has been reported to play a role in heart and kidney disease [9]. Moreover, recent studies have revealed the RAS plays an important role in the progression of many chronic liver diseases [10]. Furthermore, angiotensin II receptor blocker (ARB) modulation of the RAS to treat liver fibrosis has been reported in animal study [11].

ARBs, such as Losartan are largely regarded as a means to block vasoconstriction and inhibit the cell proliferation and fibrosis that are mediated by the angiotensin II type 1 receptor (AT1-R) [10]. Yang et al. [12] suggested that AT1-R play an important role in the development of fibrosis.

An increase in hepatic transforming growth factor $\beta 1$ (TGF- $\beta 1$ ) and pro-inflammatory cytokine levels was attenuated in AT1-R knockout mice compared to WT mice [13]. Furthermore, Bataller et al.[14] demonstrated that increased systemic Angiotensin II augments hepatic fibrosis and promotes inflammation, oxidative stress, and thrombogenic events. Losartan was reported to inhibit CCl4-induced

Correspondence to: Hisanobu Ogata, Department of Medicine and Clinical Science, Graduate School of Medical Sciences, Kyushu University, 3-1-1 Maidashi, Higashiku, Fukuoka 812-8582, Japan, Tel: +81-92-642-5256; Fax: +81-92-642-5271; E-mail: h-ogata@sentan.med.kyushu-u.ac.jp

Key words: losartan, angiotensin II type 1 receptor brocker, liver fibrosis

Received: February 01, 2016; Accepted: February 11, 2016; Published: April 15,2016 
liver fibrosis [15] and to attenuate NASH rat model [16].

In the present study, we administered losartan for repeated Concanavalin A (Con A)-treated mice with liver fibrosis. We demonstrate that losartan inhibited liver fibrosis and TGF- $\beta 1$ expression. These findings suggest that losartan downregulates TGF- $\beta 1$ expression through inhibiting RAS and then suppress the progression of liver fibrosis.

\section{Materials and methods}

\section{Animal models}

Six-week-old male C57BL/6 mice were used for the mouse liver fibrosis models. For the liver fibrosis model, these mice were administrated ConA. For the fibrosis model, mice were i.v. injected with ConA (10 mg/kg body weight) weekly for 4 weeks. At 1 day after last injection, mice were killed and their liver specimens were prepared. Mice were divided to 2 groups, losartan or control group $(n=3-5)$. In losartan group, mice were i.v. injected with losartan $(10 \mathrm{mg} / \mathrm{kg}$ body weight) weekly for 4 weeks. 1 hour before ConA injection, losartan was injected. Losartan was supplied by Banyu Pharmaceutical Co. Ltd (Tokyo, Japan). All experiments on these mice were approved by and performed in accordance with the Guidelines of the Animal Ethics Committee of Kyushu University, Fukuoka, Japan.

\section{Immunohistochemistry and Sirius red staining}

Liver tissues were fixed with $10 \%$ formalin, paraffin-embedded, and sectioned. Slides were incubated with either a 1:100 dilution of anti-TGF- $\beta 1$ (Promega) or anti- $\alpha$-smooth muscle actin (SMA) (Dako) and stained LSAB kit according to the manufacturer's instructions (Dako). The samples were then lightly stained with hematoxylin and examined. Liver fibrosis was quantified with Sirius red (Polyscience Inc.) staining as decribed [17]. The sections were incubated for $10 \mathrm{~min}$ in aqueous solution of saturated picric acid containing $0.1 \%$ Sirius red. Red-stained collagen fibers were quantitated by digital image analysis [17].

\section{Results}

\section{Losartan improved ConA-induced liver fibrosis}

First, we investigated the effect of losartan on mouse liver fibrosis. Single-injection of ConA induces acute hepatitis [18] and repeated administration of ConA is a well-established chronic hepatitis model in mice [19]. ConA-induced hepatitis also develops fibrosis after repeated liver injury, the mechanism of which is mainly based on the upregulation of TGF- $\beta 1$ expression in the liver [17]. Since ConA activates NK and NKT cells in the liver, ConA-induced fibrosis in mice has been used as a suitable model of viral hepatitis and fibrosis like human HCV infection [20].

Six-week-old male C57BL/6 mice were i.v. injected with ConA (10 $\mathrm{mg} / \mathrm{kg}$ body weight) weekly for 4 weeks. Mice were divided to 2 groups, losartan or control group. In losartan group, mice were i.v. injected with losartan $(10 \mathrm{mg} / \mathrm{kg}$ body weight) weekly for 4 weeks. In control group, mice were i.v. injected with same amount of PBS (phosphate buffered saline). At 4 weeks after ConA treatment, all mice in both groups survived. However, fibrosis levels assessed by Sirius red staining were stronger in control group than losartan group (Figure 1a). We then quantified the red-stained collagen in an image of a mouse liver tissue section stained with Sirius red by using digital image analysis [17].
A
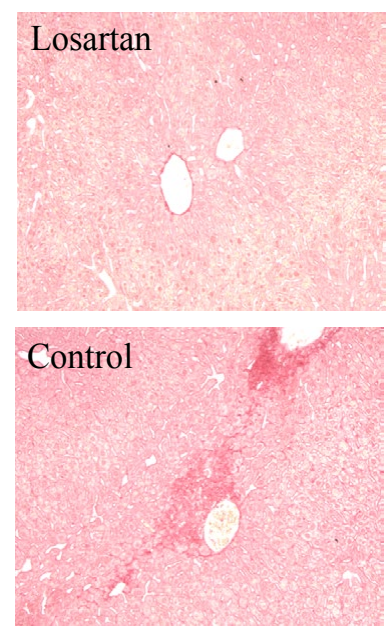

B

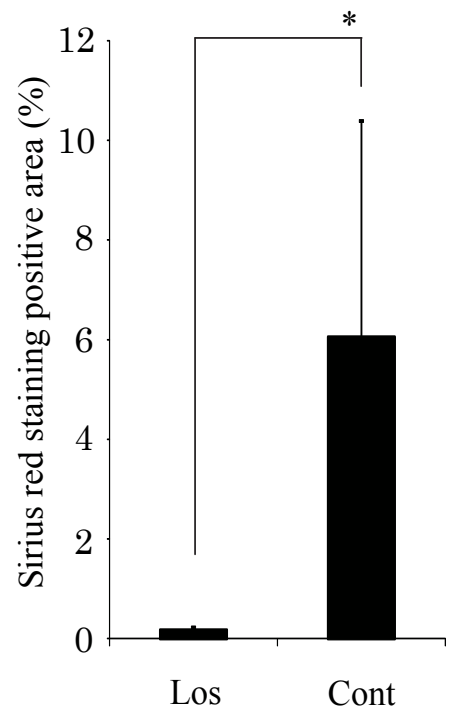

Figure 1. Losartan inhibits ConA-induced liver fibrosis.

(a) Sirius red staining in liver specimens from the ConA-injected mice (x100).

(b) The Sirius red positive area was evaluated by a digital image analyzer. Losartan significantly suppressed the ConA-induced liver fibrosis. The data are shown as the mean \pm s.e.m. $* P<0.05$.
A
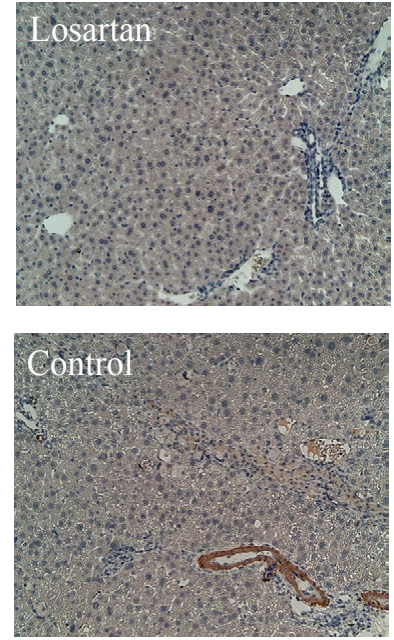

B

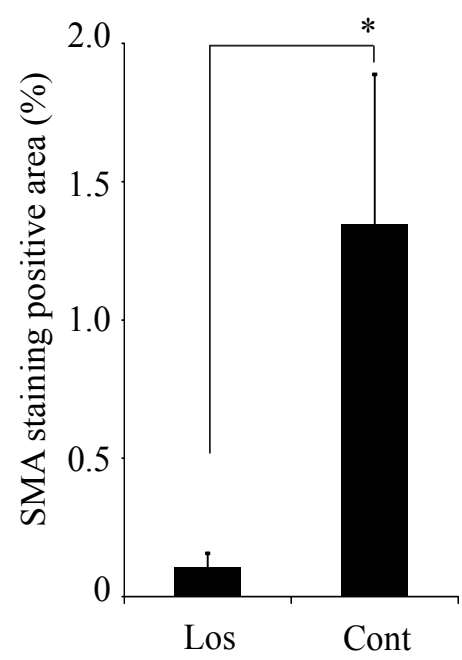

Figure 2. Losartan inhibits the activated hepatic HSCs.

(a) Immunostaining for SMA in liver specimens from the ConA-injected mice (x100) SMA-positive cell indicated the activated hepatic HSCs.

(b) SMA expression was quantitated by a digital image analyzer. Losartan significantly suppressed the activated hepatic HSCs. The data are shown as the mean \pm s.e.m. $* P<0.05$.

Sirius red staining area were much weaker in losartan-administrated mice than in control mice (Figure1b). These data indicated that an administration of losartan improved Con A-induced liver fibrosis.

Losartan suppressed CoA-induced fibrogenesis through
downregulated TGF- $\beta 1$ expression

Next, we examined the effect of the administration of losartan in 
a-Smooth muscle actin (SMA) and TGF- $\beta 1$ expressions. $\alpha$-Smooth muscle actin (SMA) localized mainly around the centrilobular area and the portal tract in the liver [17]. At 4 weeks after ConA treatment, SMA staining was much stronger in control mice than in losartantreated mice mice (Figures $2 \mathrm{a}$ and $2 \mathrm{~b}$ ). To clarify the mechanism involved in ConA-induced liver fibrosis, the TGF- $\beta 1$ expression was investigated by immunostaining. 4-week ConA treated mice showed the increased TGF- $\beta 1$ exprsssion in liver [17]. HSCs are known as the cells that produce TGF- $\beta 1$ [21]. Also, the primary hepatocytes have the ability to produce a significant amount of TGF- $\beta 1$ [22]. Losartantreatment suppressed TGF- $\beta 1$ exprsssion in both hepatocytes and nonhepatocytes including with HSCs (Figures $3 \mathrm{a}$ and $3 \mathrm{~b}$ ). Taken together, we propose that losartan negatively regulates TGF- $\beta 1$ production and then inhibits ConA-mediated liver fibrosis.

\section{Discussion}

Liver fibrosis is the excessive accumulation of extracellular matrix proteins including collagen that occurs in most types of chronic liver diseases. Advanced liver fibrosis results in cirrhosis, liver failure, and portal hypertension and often requires liver transplantation. Activated hepatic HSCs, portal fibroblasts, and myofibroblasts of bone marrow origin have been identified as major collagen-producing cells in the injured liver. These cells are activated by fibrogenic cytokines such as TGF- $\beta 1$, angiotensin II, and leptin. Reversibility of advanced liver fibrosis in patients has been recently documented, which has stimulated researchers to develop antifibrotic drugs. Emerging antifibrotic therapies are aimed at inhibiting the accumulation of fibrogenic cells and/or preventing the deposition of extracellular matrix proteins [23].

Angiotensin II type 1 receptor antagonist inhibits experimental liver fibrosis $[13,24]$. ARB inhibits rat NASH model induced by the choline-deficient L-amino acid-defined (CDAA)-diet [24]. This mechanism of inhibition is considered to depend on suppressing RAS. In this study, we have shown that losartan improves liver fibrosis
A
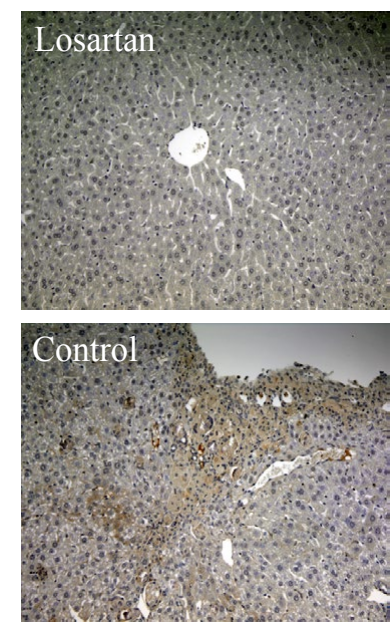

\section{B}

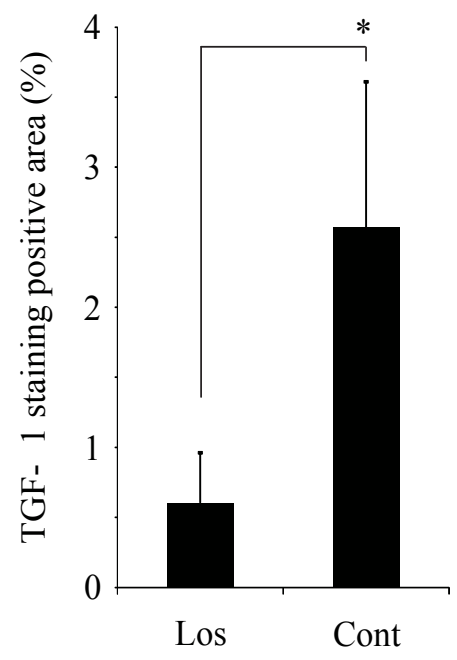

Figure 3. Losartan inhibits the TGF- $\beta 1$ expression.

(a) Immunostaining for TGF- $\beta 1$ in liver specimens from the ConA-injected mice (x100).

(b) TGF- $\beta 1$ expression was quantitated by a digital image analyzer. Losartan significantly suppressed the TGF- $\beta 1$ expression in ConA-induced mouse liver fibrosis. The data are shown as the mean \pm s.e.m. ${ }^{*} P<0.05$. and negatively regulates TGF- $\beta 1$ expression induced by ConA. Con A upregulate TGF- $\beta 1$ expression and then induce liver fibrosis [17]. RAS is an important mediator of hepatic fibrosis through activation of profibrotic mediators, such as TGF- $\beta 1$ [25].

Inhibitors of the renin-angiotensin-aldosterone system attenuate glomerulosclerosis and interstitial fibrosis. Although the mechanisms underlying their antifibrotic effects are complex, angiotensin II emerges as a major profibrogenic cytokine. Angiotensin II modulates renal cell growth, extracellular matrix synthesis, and degradation by multiple fibrotic pathways. It was reported that one of the main targets of angiotensin II in renal fibrosis is TGF- $\beta 1$ [26]. TGF- $\beta 1$ also plays an important role in liver fibrosis. ARB was reported to inhibit the progression of NASH [27]. NASH is considered as a progressive form of non-alcoholic fatty liver disease. The RAS in the liver is a potential pathway that may offer an effective therapy for liver fibrosis. Angiotensin II, the effector of the RAS, appears to play a major role in liver fibrogenesis [28]. Angiotensin II regulates cell growth, inflammation and fibrosis through activation of AT1-R. The AT1-R is locally expressed by activated HSCs, and activated HSCs generate angiotensin II $[29,30]$.

This study was undertaken to determine whether the ARB, losartan affects the progression of ConA-induced hepatic fibrosis in a mouse model of chronic hepatitis that is different from steatohepatitis such as NASH. Losartan inhibits ConA-induced hepatic fibrosis and suppress TGF- $\beta 1$ expression. Our finding of a suppression of TGF- $\beta 1$ by losartan in ConA-mediated liver fibrosis might suggest the important mechanism. In conclusion, this study provides the therapeutic potential of liver fibrosis in chronic hepatitis.

\section{Acknowledgements}

We sincerely thank Prof. Takanari Kitazono for his comments and Ms. Keiko Ohkawa for her support. This study was supported by Banyu Pharmaceutical Co. Ltd (Tokyo, Japan), JSPS KAKENHI Grant Number [19590776] and Kyushu University Short-term International Research Exchange Program which is based on Japanese Ministry of Education, Culture, Sports, Science and Technology's grant The Program for Promoting the Enhancement of Research Universities.

\section{References}

1. Sakurai T, Kudo M (2013) Molecular Link between Liver Fibrosis and Hepatocellular Carcinoma. Liver Cancer 2: 365-366. [Crossref]

2. Friedman SL (2008) Hepatic fibrosis -- overview. Toxicology 254: 120-129. [Crossref]

3. Hernandez-Gea V, Friedman SL (2011) Pathogenesis of liver fibrosis. Annu Rev Pathol 6: 425-456. [Crossref]

4. Jiao J, Friedman SL, Aloman C (2009) Hepatic fibrosis. Curr Opin Gastroenterol 25: 223-229. [Crossref]

5. Blobe GC, Schiemann WP, Lodish HF (2000) Role of transforming growth factor beta in human disease. $N$ Engl J Med 342: 1350-1358. [Crossref]

6. Meindl-Beinker NM, Dooley S (2008) Transforming growth factor-beta and hepatocyte transdifferentiation in liver fibrogenesis. J Gastroenterol Hepatol 23 Suppl 1: S122127. [Crossref]

7. P De Bleser PJ, Niki T, Rogiers V, Geerts A (1997) Transforming growth factor-beta gene expression in normal and fibrotic rat liver. J Hepatol 26: 886-893. [Crossref]

8. Pereira RM, Dos Santos RA, Teixeira MM, Leite VH, Costa LP, et al. (2007) The reninangiotensin system in a rat model of hepatic fibrosis: evidence for a protective role of Angiotensin-(1-7). J Hepatol 46: 674-681. [Crossref]

9. Dejima T, Tamura K, Wakui H, Maeda A, Ohsawa M, et al. (2011) Prepubertal angiotensin blockade exerts long-term therapeutic effect through sustained ATRAP activation in salt-sensitive hypertensive rats. J Hypertens 29: 1919-1929. 
10. Lubel JS1, Herath CB, Tchongue J, Grace J, Jia Z, et al.(2009) Angiotensin-(1-7), an alternative metabolite of the renin- angiotensin system, is up-regulated in human liver disease and has antifibrotic activity in thebile-duct-ligated rat. Clin Sci (Lond) 117: 375-386. [Crossref]

11. Moreno M, Gonzalo T, Kok RJ, Sancho-Bru P, van Beuge M, et al. (2010) Reduction of advanced liver fibrosis by short-term targeted delivery of an angiotensin receptor blocker to hepatic stellate cells in rats. Hepatology 51: 942-952. [Crossref]

12. Yang L, Bataller R, Dulyx J, Coffman TM, Ginès $P$, et al. (2005) Attenuated hepatic inflammation and fibrosis in angiotensin type la receptor deficient mice. $J$ Hepatol 43 : 317-323. [Crossref]

13. Yi ET, Liu RX, Wen Y, Yin CH (2012) Telmisartan attenuates hepatic fibrosis in bile duct-ligated rats. Acta Pharmacol Sin 33: 1518-1524. [Crossref]

14. Bataller R, Schwabe RF, Choi YH, Yang L, Paik YH, et al. (2003) NADPH oxidase signal transduces angiotensin II in hepatic stellate cells and is critical in hepatic fibrosis. J Clin Invest 112 1383-1394. [Crossref]

15. Wei YH, Jun L, Qiang CJ (2004) Effect of losartan, an angiotensin II antagonist, on hepatic fibrosis induced by CCl4 in rats. Dig Dis Sci 49: 1589-1594. [Crossref]

16. Yoshiji H, Noguchi R, Ikenaka Y, Namisaki T, Kitade M (2009) Losartan, an angiotensin-II type 1 receptor blocker, attenuates the liver fibrosis development of nonalcoholic steatohepatitis in the rat. BMC Res Notes 2: 70. [Crossref]

17. Ogata H, Chinen T, Yoshida T, Kinjyo I, Takaesu G, et al. (2006) Loss of SOCS3 in the liver promotes fibrosis by enhancing STAT3-mediated TGF-betal production. Oncogene 25: 2520-2530. [Crossref]

18. Heymann F, Hamesch K1, Weiskirchen R2, Tacke F3 (2015) The concanavalin A model of acute hepatitis in mice. Lab Anim 49: 12-20. [Crossref]

19. Kamiyoshi A, Sakurai T, Ichikawa-Shindo Y, Iinuma N, Kawate H, et al. (2009) Endogenous alpha-calcitonin gene-related peptide mitigates liver fibrosis in chronic hepatitis induced by repeated administration of concanavalin A. Liver Int 29: 642-649. [Crossref]

20. Ogata H, Kobayashi T, Chinen T, Takaki H, Sanada T, et al. (2006) Deletion of the SOCS3 gene in liver parenchymal cells promotes hepatitis-induced hepatocarcinogenesis Gastroenterology 131: 179-193. [Crossref]

21. Meurer SK, Alsamman M, Sahin H, Wasmuth HE, Kisseleva T (2013) Overexpression of endoglin modulates TGF-beta1-signalling pathways in a novel immortalized mouse hepatic stellate cell line. PLoS One 8: e56116. [Crossref]

22. Bissell DM, Wang SS, Jarnagin WR, Roll FJ (1995) Cell-specific expression of transforming growth factor-beta in rat liver. Evidence for autocrine regulation of hepatocyte proliferation. J Clin Invest 96: 447-455. [Crossref]

23. Bataller R, Brenner DA (2005) Liver fibrosis. J Clin Invest 115: 209-218. [Crossref]

24. Jin H, Yamamoto N, Uchida K, Terai S, Sakaida I (2007) Telmisartan prevents hepatic fibrosis and enzyme-altered lesions in liver cirrhosis rat induced by a choline-deficient L-amino acid-defined diet. Biochem Biophys Res Commun 364: 801-807. [Crossref]

25. Goto M, Hoxha N, Osman R, Wen J, Wells RG, et al. (2010) Renin-angiotensin system activation in congenital hepatic fibrosis in the PCK rat model of autosomal recessive polycystic kidney disease. J Pediatr Gastroenterol Nutr 50: 639-644. [Crossref]

26. Rüster C, Wolf G (2011) Angiotensin II as a morphogenic cytokine stimulating renal fibrogenesis. J Am Soc Nephrol 22: 1189-1199. [Crossref]

27. Hirose A, Ono M, Saibara T, Nozaki Y, Masuda K, et al. (2007) Angiotensin II type 1 receptor blocker inhibits fibrosis in rat nonalcoholic steatohepatitis. Hepatology 45: 1375-1381. [Crossref]

28. Bataller R, Gäbele E, Parsons CJ, Morris T, Yang L, et al. (2005) Systemic infusion of angiotensin II exacerbates liver fibrosis in bile duct-ligated rats. Hepatology 41 : 1046-1055. [Crossref]

29. Batallers R, Sancho-Bru P, Gines P, Lora JM, Al-Garawi A, et al. (2003) Activated human hepatic stellate cells express the renin-angiotensin system and synthesize angiotensin II. Gastroenterology 125: 117-125. [Crossref]

30. Paizis G, Cooper ME, Schembri JM, Tikellis C, Burrell LM, et al. (2002) Up-regulation of components of the renin-angiotensin system in the bile duct-ligated rat liver Gastroenterology 123: 1667-1676. [Crossref]

Copyright: (C2016 Ogata H. This is an open-access article distributed under the terms of the Creative Commons Attribution License, which permits unrestricted use, distribution, and reproduction in any medium, provided the original author and source are credited. 